\title{
MEASUREMENT OF THE VELOCITY FIELD BEHIND THE AUTOMOTIVE VENT
}

\author{
Tomáš LEŽovič, František LÍZAL, Jan JEDELSKÝ, Miroslav JÍCHA•
}

\begin{abstract}
Passenger comfort in a personal vehicle cabin strongly depends on the appropriate function of the cabin ventilation system. Great attention is therefore paid to the effective functioning of the automotive vents. Various techniques can be employed to evaluate the proper formation of the flow behind the ventilation outlet. Constant Temperature Anemometry (CTA) was used in our case for accurate measurement of the velocity field and consequent assessment of jet boundaries and jet axis.
\end{abstract}

\begin{abstract}
A novel methodology has been developed for the simulation of realistic conditions when using just a single vent under laboratory conditions instead of the complete vehicle ventilation system. A special technique has also been developed for determination of the terminal inclination angles of vent vanes for the particular vent type, which can be completely closed by the adjustable horizontal vanes.
\end{abstract}

A two wire CTA probe was used for measurement of the actual velocity over predefined planes, which were specified according to smoke visualization. Mean velocities and the turbulence intensity were evaluated on the basis of the obtained data and are presented in a form of charts. Both jet boundary and orientation of the jet for a given setup of the vent are important characteristics of particular vent type. Effectiveness of different vents could be compared using our methodology and hence contribute to development of advanced ventilation system.

\section{INTRODUCTION}

Creation of optimal microclimate in a car is an important part of the car industry. Since the beginning of the $20^{\text {th }}$ century there has been an effort to provide a sufficient comfort to passengers. Thus, more effective and advanced car ventilation systems are under constant development. Measurement of the indoor air quality parameters such as air and surface temperatures, air flow velocity, turbulence intensity, etc., is an inseparable and necessary part of the further development of ventilation systems in cars [1].

Our project is dealing with one of the segments of the car ventilation system. Our main interest focuses on the side automotive vent of the car dashboard (see Fig. 1). It is such a vent, that can employ the adjustable vanes to close the vent completely (the particular vent used for experiments was taken from the model Skoda Octavia).

\footnotetext{
•Tomáš Ležovič, František Lízal, Jan Jedelský, Miroslav Jícha, Brno University of Technology, Faculty of Mechanical Engineering, Technická 2, 61669 Brno, Czech Republic, ylezov01@stud.fme.vutbr.cz
} 
The improvement of air distribution within a car cabin and passengers' satisfaction with the microclimatic comfort in a car cabin is the main motivation of the project. It is expected that data will be helpful for innovation of the used vent, or it will help with the design of a new vent of a similar type.

For the evaluation of the vent air flow

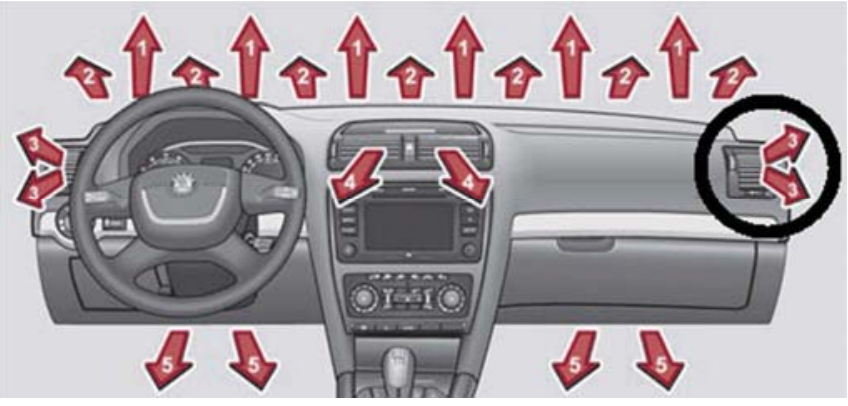

Figure 1 Image of the used vent [2] such parameters were chosen, that are based on user's demand on vent. A vent should direct air flow properly and distribute a fair amount of air to the adequate distance. Therefore these parameters for measurement were chosen: the jet axis, the jet boundaries and orientation of the jet in the car cabin, and terminal inclination angles of vent vanes.

The main objective of the project was to develop a new methodology for measurement of selected parameters of the air flow from a vent. The methodology must be generally usable, repeatable and the experimental device for application should be as simple as possible. Another aim is to apply the methodology to the experimental device.

The measurement of the velocity field is possible with the use of various methods. For example mechanical anemometers, HWA methods (Hot Wire Anemometry), LDA methods (Laser Doppler Anemometry), PTV (Particle Tracking Velocimetry), PSV (Particle Streak Velocimetry), or PIV (Particle Image Velocimetry), etc. are used. In the research of the flow, numerous CFD softwares are used, which predict the flow based on numerical models. In this way, it may be cheaper and quicker than implementation of the real measurement. But every model has to be brought to the real situation. Therefore the measurement of actual values of the flow velocities, turbulence and other data is still needed for validation of numerical models, determination of boundary conditions, etc. For velocity field measurement, in front of vent, we have chosen hot wire anemometry, specifically CTA (Constant Temperature Anemometry), in combination with smoke visualization. Smoke visualization provides only qualitative results, while CTA provides also quantitative results [3].

\section{Methodology}

\section{Methodology of terminal vertical direction (MTVD)}

As mentioned above, the object of the research is an automotive vent, which can be completely closed by the adjustable horizontal vanes. Movement of horizontal vanes does not influence only inclination of the vent air flow, but also its amount. It is important to find out at what inclination of the vanes the amount of the air supplied to the space of the car cabin is still sufficient for passengers' comfort. Then we speak about so called "terminal inclination angle" of vent vanes, when the vent still fulfils its function. At greater inclination angles, the supplied amount of air will not be sufficient.

The first point is to quantify the change of flow caused by vertical adjustment of vent vanes. It is necessary to determine at which percent decline of the flow the vent still fulfils its function. An experimental test was made, during which the air flow was 
decreased and subjective feelings of a person sitting in a sufficient distance from vent were noted (approximately the same distance from the vent as of the person sitting in the front car seat). During the observation at which the person noticed the change (decrease) of the air flow rate more distinctively, the final value of flow rate change was determined. Flow rate change used for MTVD: $\Delta Q=30 \%$.

The methodology of the terminal vertical direction must reflect the real car ventilation system. We have developed and applied a measuring method which is usable, generally, on the similar measuring devices. The method requires a minimum of the measured and

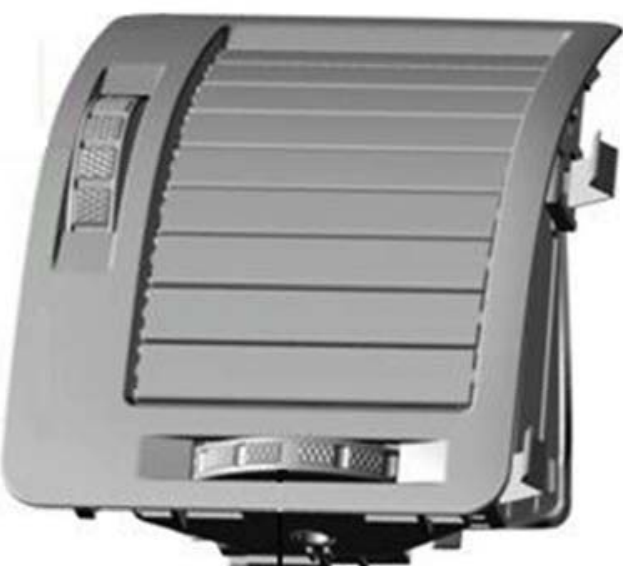

Figure 2 The used automotive vent adjusted values.

In the suggested measuring device only one vent is mounted, while, in a real, several vents are mounted to an air pipe line. Changes of the air flow rate at various adjustments of vent vanes are proved very differently in both systems.

To account for this fact, a special measurement methodology has been developed. The main idea of this methodology lies in the derivation of the mathematical relationship, which expresses the change of the pressure loss coefficient of the regulated vent $\xi$ depending on the determined air flow rate change. It is not necessary to know the value of the coefficient $\xi$, because the change of it is determined as the ratio of $\xi_{0}$ (before any adjustment) and $\xi_{1}$ (after adjustment).

Several conditions and assumptions are discussed and an analogy with an electric circuit is employed during the relationship derivation.

The derived relationship is relevant for the ventilation system with parallel plugging of $n$ identical branches. It is necessary to simplify the real ventilation system in a car according to this scheme. Simplification for the particular case of our project is in Fig. 3 .

a)

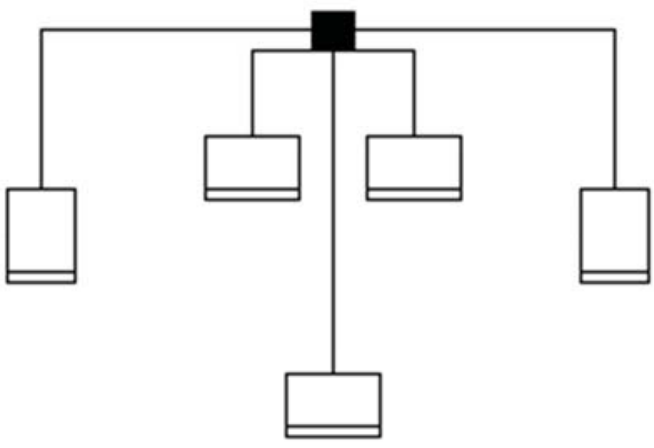

b)

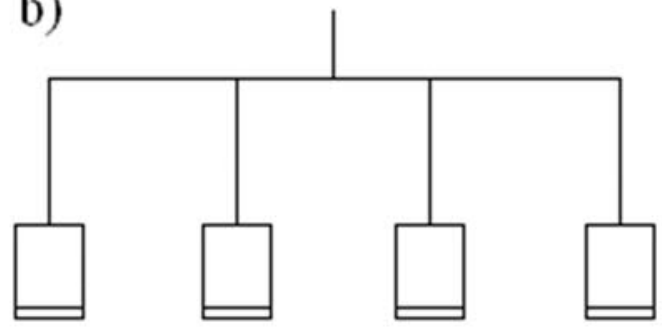

Figure 3 The scheme of the real vent system (a) and its simplification (b). 
The final formula for relation of the pressure loss coefficients ratio $x$ :

$$
x=\frac{\xi_{1}}{\xi_{0}}=\frac{n-r^{2}}{(n-1) r^{2}}
$$

Where $r$ is ratio of air flow rates:

$$
r=\frac{Q_{1}}{Q_{0}}=\frac{v_{1} \cdot S}{v_{0} \cdot S}=\frac{v_{1}}{v_{0}}
$$

The other formulation of the pressure loss coefficient ratio $x$ :

$$
x=\frac{\xi_{1}}{\xi_{0}}=\frac{2 \Delta p_{1} S^{2}}{Q_{1}{ }^{2} \varrho}: \frac{2 \Delta p_{0} S^{2}}{Q_{0}{ }^{2} \varrho}=\frac{\Delta p_{1}}{\Delta p_{0}} \cdot \frac{Q_{0}^{2}}{Q_{1}^{2}}=\frac{\Delta p_{1}}{\Delta p_{0}} \cdot \frac{1}{r^{2}}
$$

Pressure loss $\Delta p_{1}$ from the equation (3):

$$
\Delta p_{1}=x \cdot \Delta p_{0} \cdot r^{2}=x \cdot \Delta p_{0} \cdot\left(\frac{v_{1}}{v_{0}}\right)^{2}
$$

From equation (4) is calculated the value of the pressure loss of that part of the ventilation system where the examined vent is. Equation (4) contains values of $r$ and $\Delta p_{0}$, which stand for the ratio of air flow rates determined and pressure loss measured, respectively. The influence of multiple vents connection is represented by the pressure loss coefficients ratio $x$, which is calculated from equation (1). The horizontal vanes of the vent are then adjusted so the pressure loss of the measuring device is the same as the one obtained using equation (4). These parameters are controlled by the device: $v_{0}$, $v_{1}, \Delta p_{0}, \Delta p_{1}$. After the adjustment of the required values, the terminal inclination angles of vanes are measured. The measuring process is repeated several times, the vent vanes are set up and down in sequence. The result is the value of lower and upper terminal inclination angle.

\section{Methodology of the measurement of the velocity field and consequent assessment of jet boundaries and jet axis}

For determination of the jet boundaries and jet axis is measured velocity field of vent air flow. Method of smoke visualization and HWA method, specifically CTA, is used. The smoke visualization method precedes more sophisticated CTA method. Configuration of the CTA measurement is based on the smoke visualization results. The basic principle of the CTA is convective heat transfer from a heat sensor to the surrounding fluid. Convective heat transfer equation (6) must be in balance with the equation of the electric power for heating element (7).

$$
\begin{gathered}
Q=\alpha S\left(t_{w}-t_{\infty}\right) \\
P=R I^{2}
\end{gathered}
$$


HWA method is completely described by Bruun [3], more information about the applied CTA device can be found in $[4,5]$.

\section{Measuring process}

The vent has a horizontal and vertical vanes. The flow field was measured for three different positions of the vanes. The vertical vanes were set to the middle position and the position of horizontal vanes was adjusted. The measurement was taken when the horizontal vanes were set to the middle position, to the lower limit position (Lower Terminal Inclination Angle LTIA) and to the upper limit position of the vanes (Upper Terminal Inclination Angle - UTIA). Each set of

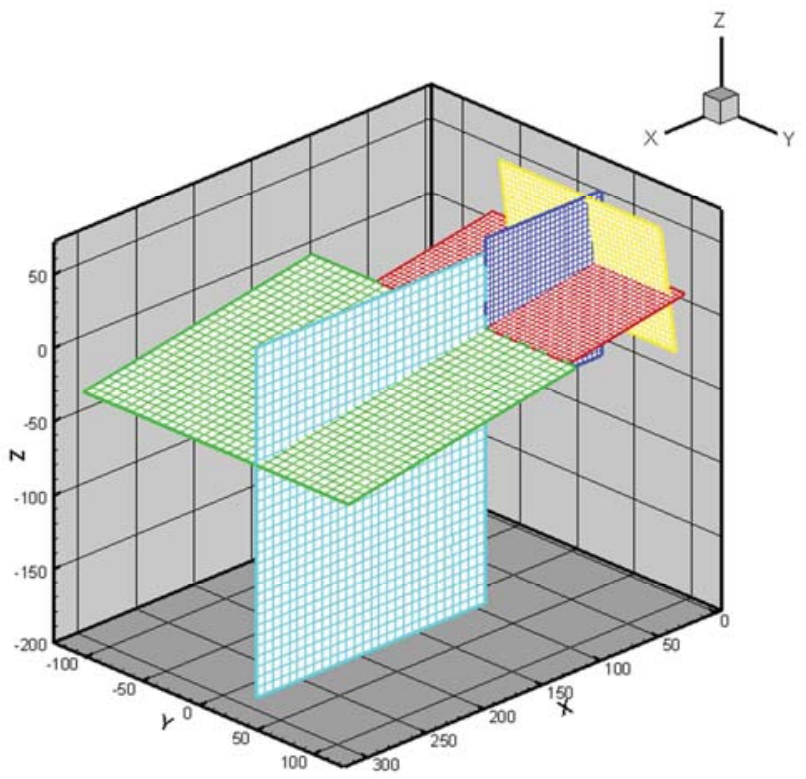

\section{Figure 4 Measuring planes for LOWER - MIDDLE} measurements was named according to the position of the fins (HORIZONTAL - VERTICAL). Nomenclature of measurements: LOWER - MIDDLE, MIDDLE - MIDDLE, UPPER - MIDDLE. Measuring planes of CTA were defined separately for each position of vanes.

The smoke visualization was performed at first. According to the results of smoke visualization, the measuring planes for CTA were defined. We selected the appropriate CTA probe next. It was Dantec 55P61 dual sensor probe in our case. The measurement by CTA anemometer runs automatically, the probe moved along the defined measuring planes while taking the values of the air speed and turbulence intensity at specified points of the plane. The results were evaluated by Tecplot software. The collected data were used to define the jet boundary and its axis.

The air speed at the jet boundary was defined and relevant points from the collected data were selected. The absolute value of boundary velocity was selected $1 \mathrm{~m} / \mathrm{s}$ in our case. We have highlighted the jet boundary by placing a line in between these points suitably. The jet axis was determined at the geometric centre in between detected jet boundaries.

\section{Measuring device}

A measuring device for the experiment was assembled, the theoretical analysis preceded it. The device, as seen in Fig. 5, consisted of a suction pipe, fan, filter, supply pipe and a vent. The vent was placed in sufficient distance from the laboratory walls to avoid their influence on the flow (information about it in $[6,7]$ ). The experimental device used untreated laboratory room air. External conditions (pressure, temperature, humidity) were measured using Comet D4141 in this experiment. The air temperature at the inlet and at the outlet of the vent was measured using resistance thermometer pt100. The values taken were fed to LabView software. Digital micromanometer MEDM 500 was used to measure the difference in the pressure before and behind the vent. The air flow rate in the pipe was measured by method of the local velocity in cross section to determine the flow (more information about method can be found in [8]). The velocity profile was 
measured using TESTO 454 anemometer and hot bulb probe. StreamLine anemometer from Dantec Dynamics was used for the CTA measurement, this device is using StreamWare software [5]. Tecplot software was used to create 2D and 3D graphs of the velocity magnitude and turbulence intensity.

\section{Definition of the air flow rate}

The air flow rate was set to be $30 \mathrm{~m}^{3} / \mathrm{h}$ as it is the most common in real operation (this fact was consulted with technician from Skoda Auto). This value was the input parameter for both the MTVD and velocity field by CTA method.

Definition of the coordinate system

The vehicle coordinate system was defined as follows: the $X$ axis is horizontal and passes through the car along its length, the $Y$ axis is also horizontal and passes transversely to the length of car, the $Z$ axis is vertical. The laboratory coordinate system agreed with the vehicle coordinate system, the vent was located in the identical position to the coordinate system in laboratory as in the real vehicle. The jet boundaries and the jet axis were related to the chosen coordinate system. The angles were put into the $X Y$ plane and $X Z$ plane.

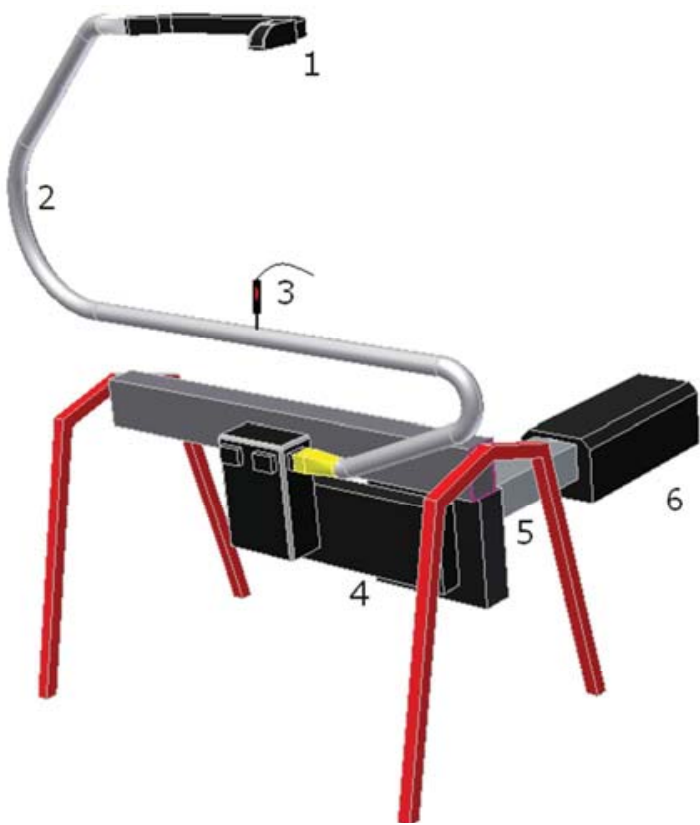

Figure 5 Measuring device; vent (1), supply pipe (2), hot bulb probe (3), fan and filter (4), suction pipe (5), fog generator (6)

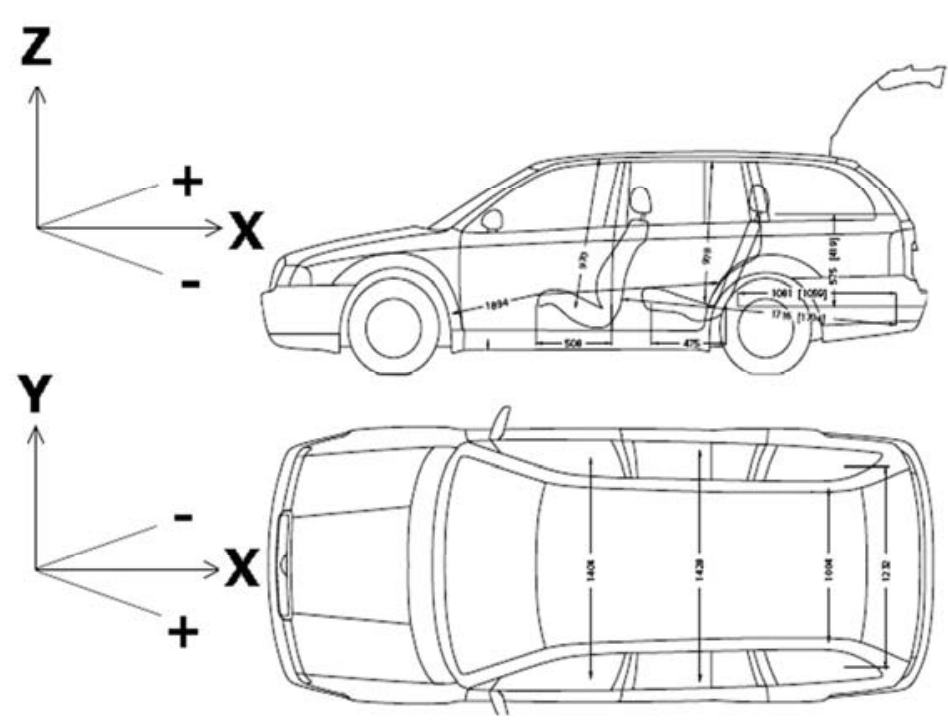

Figure 6 Coordinate system and orientation of the angles 


\section{REsults}

The experiment was carried out on the right side vent of the Skoda Octavia the second generation. Complete results of the experiments are presented in the attachment of the author's diploma thesis [9].

\section{Results of the measurement MTVD}

Input parameters:

Air flow rate $Q_{0}=30 \mathrm{~m}^{3} / \mathrm{h}$

Limit change of flow rate $\Delta \mathrm{Q}=30 \%$

For these input parameters the terminal angles of vanes were determined:

UTIA (in the XZ plane) $104,5^{\circ} \pm 3^{\circ}$

LTIA (in the XZ plane) $\quad-6^{\circ} \pm 3^{\circ}$

The expanded uncertainly is a product of the standard uncertainly and coverage coefficient $\mathrm{k}=2$, which corresponds to a normal expected coverage of $95 \%$ [10].

\section{Measured flow field results}

Input parameters:

Air flow rate $Q_{0}=30 \mathrm{~m}^{3} / \mathrm{h}$

\section{Table 1 Fins adjustment}

\begin{tabular}{|l|c|c|c|}
\hline VANES SETTING & $\begin{array}{c}\text { LOWER - } \\
\text { MIDDLE }\end{array}$ & $\begin{array}{c}\text { MIDDLE - } \\
\text { MIDDLE }\end{array}$ & $\begin{array}{c}\text { UPPER - } \\
\text { MIDDLE }\end{array}$ \\
\hline Angle of horizontal fins in plane $X Z\left(1^{\circ}\right)$ & -6 & 50 & 104,5 \\
\hline Angle of vertical fins in plane $X Y\left(1^{\circ}\right)$ & 11 & 11 & 11 \\
\hline
\end{tabular}

The angles of jet boundaries and jet axes identified in measuring planes were projected into the $X Y, X Z$ planes of the coordinate system of the car. The table 2 presents results for all measurements (three different vanes set-ups, repeated measurement).

Table 2 The results of angles of jet edges and jet axis

\begin{tabular}{|l|c|c|c|c|c|c|}
\hline \multirow{2}{*}{ VANES SETTING } & \multicolumn{2}{|c|}{$\begin{array}{c}\text { LOWER - } \\
\text { MIDDLE }\end{array}$} & \multicolumn{2}{c|}{$\begin{array}{c}\text { MIDDLE - } \\
\text { MIDDLE }\end{array}$} & \multicolumn{2}{c|}{$\begin{array}{c}\text { UPPER - } \\
\text { MIDDLE }\end{array}$} \\
\hline Plane & $\mathrm{XY}$ & $\mathrm{XZ}$ & $\mathrm{XY}$ & $\mathrm{XZ}$ & $\mathrm{XY}$ & $\mathrm{XZ}$ \\
\hline Angle of left (lower) jet boundary $\left(1^{\circ}\right)$ & $-1,8$ & $-16,9$ & $-15,4$ & 46,3 & 199,6 & 109,3 \\
\hline Angle of jet axis $\left(1^{\circ}\right)$ & 7,5 & $-10,5$ & 1,2 & 50,1 & 189,3 & 116,9 \\
\hline Angle of right (upper) jet boundary $\left(1^{\circ}\right)$ & 16,9 & $-4,1$ & 17,7 & 53,9 & 178,9 & 124,6 \\
\hline
\end{tabular}

The additional 3D graphs were processed from data collected during measurement LOWER - MIDDLE. These graphs are presenting velocity magnitude and turbulence intensity when the vanes were set into this position. The complex results of measurements for each vanes set-up can be found in [9]. 

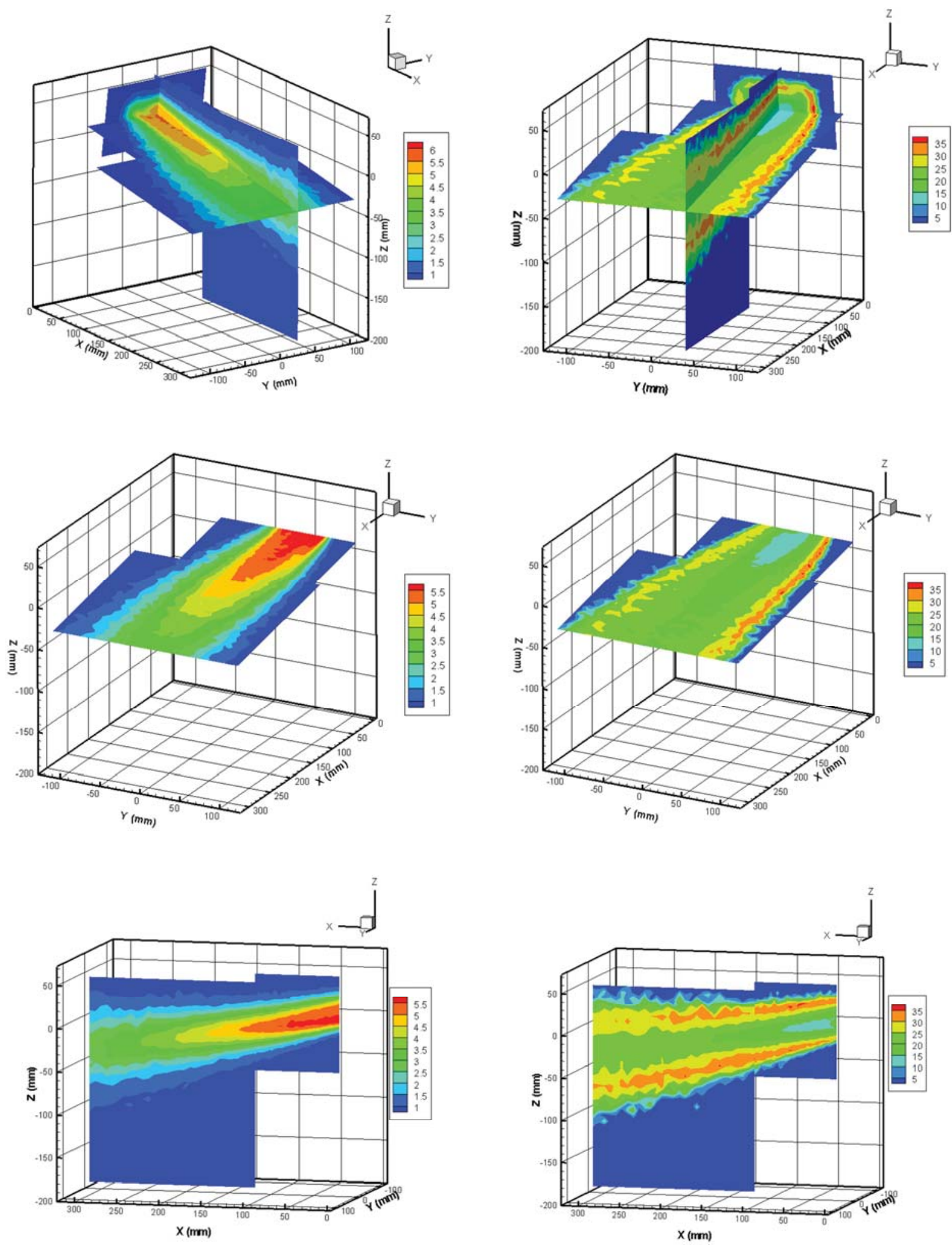

Figure 7 Setting LOWER - MIDDLE. 3D graphs of velocity magnitude and turbulence intensity. Velocity fields $(\mathrm{m} / \mathrm{s})$ are in the left figures, turbulence intensity fields (\%) in the right 


\section{Discussion}

By applying the MTVD, we obtained the final terminal angles of the examined vent. The UTIA is $104,5^{\circ} \pm 3^{\circ}$. When turning the vanes above this limit it would decrease the air flow in the vent by more than $30 \%$ of the initial flow (based on fully open vent). We get same results when trying to exceed the LTIA, whose value is $-6^{\circ} \pm 3^{\circ}$.

We can find out the terminal inclination angles for similar types of vents with the use of the MTVD methodology. The default parameters for MTVD are defined by the initial air flow rate through the fully open vent and also through the limit of the percentage flow rate drop while closing the vent. We determined this limit be $30 \%$ from the initial flow rate in our project which was $30 \mathrm{~m}^{3} / \mathrm{h}$. These parameters can be set to different values according to the client's requirements. The values of the angles will be different for each specific parameter.

Results obtained from measurements of flow fields provide us with an overall view of the flow of the vent. We can clearly see the air speed and the turbulence intensity levels for each position on the 3D graphs.

Based on the known jet boundaries and axis, we can evaluate the direction of the air leaving the vent. By comparing the angle of the jet axis with the angle of the vanes we can assess the capability of the vent to aim the air flow within the space. The jet boundary angles show the affected area by the flow. They also show the jet orientation inside the car cabin.

Table 3 Difference between jet axis angles and angles of fins

\begin{tabular}{|l|c|c|c|c|c|c|}
\hline VANES SETTING & \multicolumn{2}{|c|}{ LOWER - MIDDLE } & \multicolumn{2}{c|}{ MIDDLE - MIDDLE } & \multicolumn{2}{c|}{ UPPER - MIDDLE } \\
\hline Plane & $\mathrm{XY}$ & $\mathrm{XZ}$ & $\mathrm{XY}$ & $\mathrm{XZ}$ & $\mathrm{XY}$ & $\mathrm{XZ}$ \\
\hline Angle of jet axis $\left(1^{\circ}\right)$ & 7,5 & $-10,5$ & 1 & 50 & 189 & 117 \\
\hline Angle of fins $\left(1^{\circ}\right)$ & 11 & -6 & 11 & 50 & 191 & 104,5 \\
\hline Absolute difference $\left(1^{\circ}\right)$ & 3,5 & 4,5 & 10 & 0 & 2 & 12,5 \\
\hline
\end{tabular}

We get information about the velocity magnitude and turbulence intensity in the flow field by using CTA method. These data are very valuable. As they provide information about what is the air flow velocity and turbulence intensity in different distances from the vent (for example in the vicinity of the passenger seat). The turbulence intensity has an effect on the comfort of passengers and it is one of the values included in the evaluation of the environment in the car.

\section{CONCLUSION}

We have analysed the side vent of a car ventilation system. As a result of this study we have proposed parameters by which we can evaluate the function of vents. A methodology has been developed for measuring these parameters. For this methodology, the hot wire anemometry was used, specifically CTA method. CTA method is suitable for measuring the ventilation system of a car cabin, unfortunately, the applied CTA method is rather time-consuming. By employing the methodology we have obtained data on air speed and turbulence intensity in the jet entering the car cabin. These variables affect significantly the passengers' comfort. 
This project should serve to further development of a modern ventilation system. With the proposed methodologies we can measure similar types of vents and compare them. The evaluation of quality of vents and comparison of different vents should contribute to the development of modern and more advanced vents.

\section{ACKNOWLEDGEMENTS}

The authors gratefully acknowledge Pavel Ruzicka (EVEKTOR, spol. s r.o.), Petr Sedivy and Jan Klimes (SKODA AUTO a.s.) for their consultations and providing us with the components for testing. The work was financially supported by the project GA101/09/H050 founded by the Czech grant agency and the project of the Brno University of Technology FSI-S-11-6.

\section{Nomenclature}

I electric current going through the sensor (A)

$r \quad$ ratio of air flow rates (-)

$n \quad$ number of identical branches of the ventilation system (-)

$Q \quad$ flow rate $\left(\mathrm{m}^{3} / \mathrm{h}\right)$

$R \quad$ electric resistance of the sensor $(\Omega)$

$S \quad$ cross-sectional area of the duct $\left(\mathrm{m}^{2}\right)$

$S$ sensor surface area $\left(\mathrm{m}^{2}\right)$

$t_{\infty} \quad$ flowing fluid temperature $\left({ }^{\circ} \mathrm{C}\right)$

$t_{w} \quad$ sensor surface temperature $\left({ }^{\circ} \mathrm{C}\right)$

$v \quad$ mean flow velocity $(\mathrm{m} / \mathrm{s})$

$a \quad$ convection heat transfer coefficient $\left(\mathrm{W} / \mathrm{m}^{2} / \mathrm{K}\right)$

$\Delta p_{1} \quad$ pressure loss of the ventilation system branch $(\mathrm{Pa})$

$\xi \quad$ pressure loss coefficient (-)

$\rho \quad$ air density (it is a constant during the experiment) $\left(\mathrm{kg} / \mathrm{m}^{3}\right)$

index $x_{0}$ the vent is fully open

index $x_{1}$ the vent is partly open

\section{RefEREnces}

[1] DALY, S. Automotive Air Conditioning and Climate Control Systems. [s.I.]: Butterworth-Heinemann, 2006. 432 s. ISBN 0-7506-6955-1.

[2] ŠKODA AUTO A.S. - model Skoda Octavia, facts, technical data, gallery [online]. c2010 [cit.2010-12-13], <http://www.skoda-auto.cz>

[3] BRUUN, H. Hot-Wire Anemometry: Principles and Signal Analysis. Oxford: Oxford University Press, 1995. 507 s. ISBN 0-19-856342-6.

[4] JØRGENSEN, F. How to measure turbulence with hot-wire anemometers: a practical guide. 1st edition. [s.I.]: Dantec Dynamics A/S, 2001. 56 s.

[5] Dantec Measurement Technology A/S. StreamLine/StreamWare: Installation \& User's guide. 1st edition. [s.1]: [s.n.], c2000. 3 sv. (96, 178, 118 s.).

[6] AWBI, H. Ventilation of buildings. London: Spon press, 2003. 536 s. ISBN 0 415-27056-1.

[7] CHYSKÝ, J.; HEMZAL, K., a kol. Větrání aklimatizace: Technický průvodce. Praha: Bolit - B press Brno,1993.560 s. ISBN 80-901574-0-8.

[8] PAVELEK, M.; ŠTETINA, J. Experimentální metody $v$ technice prostředí. Brno: Akademické nakladatelství CERM, 2007. 215 s. ISBN 978-80-214-3426-4

[9] LEŽOVIČ, T. Experimentální analýza proudu vzduchu z ofukovače osobního vozu s využitím žárového anemometru a návrh hodnocení kvality ofukovače. Brno: Vysoké učení technické v Brně, Fakulta strojního inženýrství, 2011. 90 s.

[10] NĚMEČEK, P. Nejistoty měření. Praha: Česká společnost pro jakost, o. s., 2008. $96 \mathrm{s.}$ 